\title{
Oral Health Literacy and Oral Health Knowledge among 2,263 First-time Pregnant Urban Women: A Cross-sectional Questionnaire Study
}

\author{
Shrikanth Muralidharan ${ }^{1}$, Pramila Mallaiah ${ }^{2}$, Sakharam Garale ${ }^{3}$, Arunkumar Acharya ${ }^{4}$
}

\begin{abstract}
Aim: The present study aimed to see the oral health literacy rate among first-time pregnant women across 12 corporate hospital setups in the city of Pune, India.

Materials and methods: For the survey, the REALD 30 questionnaires were used to assess the adult literacy rate (with 0 being least score and 30 being the highest score) and the knowledge of the participants related to oral health was assessed using a set of 6 questions. The study was carried out for a period of 1 year from January 2018 to December 2018. The total participants at the end of the study were 2,263. All the women were pregnant for the first time, in their 1st trimester of pregnancy. Written consent was taken from all the participants. Epi Info was used to carry out the statistical analysis. All the $p$ values less than 0.05 was considered to be statistically significant.

Results: The mean REALD 30 score was $23.8 \pm 8.34$. The REALD score was higher for those with a postgraduate degree; this could be due to more number of participants in the group. There were higher percentages of women with correct answers to all the knowledge-based questions. We observed that there was a positive correlation with the REALD total scores and the correct answers provided to the questions on oral health $(r=0.76)$. There was a positive correlationship between the REALD scores and the oral health knowledge of the participants.

Conclusion: The educated pregnant women had a high oral health literacy rate. There was a positive correlation of literacy with the REALD 30 score.

Clinical significance: Healthcare providers should focus on clearing the myths and misconceptions that are still prevalent in a small portion of the urban population.

Keywords: Literacy, Oral health, Pregnancy.

The Journal of Contemporary Dental Practice (2019): 10.5005/jp-journals-10024-2657
\end{abstract}

\section{INTRODUCTION}

Caring for a child begins from the pregnancy stage itself. It's the mother's nutrition and her state of health that directly influences the growth and development of the child. It is a common consensus through decades of experiences with regard to oral health integration as a part of primary healthcare procedure for pregnant women and the infant. 'Since a women's body undergoes a number of changes through puberty, motherhood, and menopause, it is important to give special attention to the changes and its effect on oral health. The mother's health affects the child directly and therefore much care is needed. ${ }^{2-6}$ Pregnancy presents with a wide range of oral diseases such as gingivitis, xerostomia, erosions due to repeated vomiting, ptyalism, tooth mobility, and pyogenic granuloma. ${ }^{6,7}$ Periodontal tissue has been the most widely studied aspect among pregnant women, and association between preterm low birth weight and periodontitis is known. A poor maternal health has been associated with preeclampsia and a higher tooth decay experience by the child owing to salivary transmission by the mother. ${ }^{8}$ Therapeutic interventions related to maintaining oral health such as scaling, curettage, restorations are considered safe during pregnancy, which avoid further negative consequences for both the mother and the child. ${ }^{1-9}$ Early healthcare promotion during pregnancy has been reported to improve the overall oral health in children. ${ }^{2}$ There is a strategy buildup in relation to oral health provisions as a part of the healthcare across the globe. India remains an exemption to the same with no special policy in place for mother and child oral health. India is no longer in the low-income
${ }^{1}$ Department of Public Health Dentistry, MA Rangoonwala College of Dental Sciences and Research Centre, Pune, Maharashtra, India

${ }^{2}$ Department of Public Health Dentistry, Mathrusri Ramabai Ambedkar Dental College and Hospital, Bengaluru, Karnataka, India

${ }^{3}$ Renovare Healthcare Solutions, Navi Mumbai, Maharashtra, India

${ }^{4}$ Department of Public Health Dentistry, Navodaya Dental College and Hospital, Raichur, Karnataka, India

Corresponding Author: Shrikanth Muralidharan, Department of Public Health Dentistry, MA Rangoonwala College of Dental Sciences and Research Centre, Pune, Maharashtra, India, Phone: +91 8308008831, e-mail: shrikanthmuralidharan23@gmail.com

How to cite this article: Muralidharan S, Mallaiah P, et al. Oral Health Literacy and Oral Health Knowledge among 2,263 First-time Pregnant Urban Women: A Cross-sectional Questionnaire Study. J Contemp Dent Pract 2019;20(9):1029-1032.

Source of support: Nil

Conflict of interest: None

nations group, with more and more medical seats, accessibility to healthcare, and many national and international agencies providing services in relation to health, it is interesting to see that oral health does lose out on the fair share. Any special training to healthcare providers for pregnant women and oral health is missing and oral health is not a part of the integral services across India. ${ }^{7}$ Public awareness campaigns are also missing, unlike those for TB, 
HIV, and safe abortions. This lacuna may in future be able to be a contributing factor to other etiologies for the health of the mother as well as the child. ${ }^{7}$ The present study is thus aimed to evaluate the oral health literacy rate among the first-time pregnant women across 12 corporate hospital setups in the city of Pune, India.

\section{Materials and Methods}

Ethical clearance was obtained from the Ethics Committee of M.C.E. Society, Azam Campus, Pune before the start of the study. For the survey, the REALD (Rapid Estimation of Adult Literacy in Dentistry)-30 questionnaire was used to assess the adult literacy rate (with 0 being least score and 30 being the highest score) and the knowledge of the participants related to oral health was assessed using a set of 6 questions. ${ }^{10}$ Permission was sought from the 12 corporate hospitals catering to pregnant women healthcare needs across the city of Pune. The study was carried out for a period of 1 year from January 2018 to December 2018. The total participants at the end of the study were 2,263 . All the participating women were pregnant for the first time, in their 1st trimester of pregnancy. A written consent was taken from all the participants. No incentives were provided to be a part of the study. The questions were typed in English and handed over to the participants to be filled out. Demographic data related to age, date of birth, level of education, occupation, monthly income, religion, and any systemic illness were recorded. Any queries related to the questionnaire were explained to the participant. The participants were provided with information regarding the importance of oral health by distribution of pamphlets at the end of the interview. The data collected were entered in Microsoft excel 2013. Epi Info was used to carry out the statistical analysis. All the $p$ values less than 0.05 was considered to be statistically significant.

\section{Results}

There were 2,263 women from whom the data were collected. All the women were well educated (graduate and above) and from a high socio-economic status. Table 1 shows the demographic data of the study participants. All the women were educated (medium was English), with 91.2\% were postgraduates (Table 1). The mean REALD 30 score was $23.8 \pm 8.34$. The REALD score was higher for those with a postgraduate degree; this could be due to more number of participants in the group. Table 2 shows the questions asked for assessing the basic knowledge of the women with respect to oral health. Only $6.9 \%$ responded that mother's oral health had no effect on the child's oral health; $82.5 \%$ disagreed that cleaning of the baby's teeth is not important; $88.4 \%$ were aware that a child's overall health is affected by cavities in the teeth; $75.1 \%$ said that one should not visit the dentist only if it hurts; $65.7 \%$ agreed that tooth decay can spread to other parts of the body also; the majority of mothers (87.8\%) agreed that regular dental visits can prevent dental problems in the long run. Overall, we observed a higher percentage of women providing correct answers to all the knowledge-based questions. We tried to see whether any co-relation exists between the knowledge of oral health and the REALD score. We observed that there was a positive co-relation with the REALD total scores and the correct answers provided to the questions on oral health $(r=0.76)$. There was a positive co-relationship between the REALD scores and the oral health knowledge of the participants (Table 3 ).

Table 1: Demographic distribution of the study participants

\begin{tabular}{lcc}
\hline Item recorded & Number & Percentage \\
\hline Mean age: $26.45 \pm 5.46$ & & \\
Religion & & \\
$\quad$ Hindu & 1,894 & 83.7 \\
$\quad$ Christian & 369 & 16.3 \\
Total & 2,263 & 100 \\
\hline All were from the upper middle class as per the Kuppuswamy scale classification (2018) \\
\hline Studied in English medium & 2,263 & 100 \\
Level of education & & 8.8 \\
$\quad$ Graduate & 200 & 91.2 \\
$\quad$ Postgraduate & 2,063 & 100 \\
Total & 2,263 & \\
\hline
\end{tabular}

Table 2: Distribution of the response to the oral health knowledge questions

\begin{tabular}{|c|c|c|c|}
\hline Questions & Agreen (\%) & Disagree $n(\%)$ & Not sure $n(\%)$ \\
\hline Mothers oral health has no effect on the child's oral health & $156(6.9)$ & $2,107(93.1)$ & $00(0.0)$ \\
\hline $\begin{array}{l}\text { Cleaning of the baby's teeth is not important, since they fall of after a } \\
\text { few years }\end{array}$ & $194(8.6)$ & $1,867(82.5)$ & $202(8.9)$ \\
\hline A child's overall health is not affected by cavities in the tooth/teeth & $200(8.8)$ & $2,000(88.4)$ & $63(2.8)$ \\
\hline A cavity should be filled only if it hurts the child & $564(24.9)$ & $1,709(75.1)$ & $00(0.0)$ \\
\hline $\begin{array}{l}\text { Tooth decay in baby teeth can cause infections that can spread to the } \\
\text { face and other parts of the body }\end{array}$ & $1,486(65.7)$ & $100(4.4)$ & $677(29.9)$ \\
\hline Regular visit to the dentist helps to prevent oral problems on the long run & $1,987(87.8)$ & $274(12.1)$ & $02(0.1)$ \\
\hline
\end{tabular}


Table 3: Correlation of mean REALD score with the correct response provided to the oral health knowledge

\begin{tabular}{|c|c|c|c|}
\hline Question & $\begin{array}{l}\text { Correct } \\
\text { responsen (\%) }\end{array}$ & $\begin{array}{l}\text { Mean REALD } \\
\text { score }\end{array}$ & $\begin{array}{l}\text { Pearson's } \\
\text { coefficient }\end{array}$ \\
\hline Mother's oral health has no effect on the child's oral health & $2,107(93.1)$ & 22.1 & 0.86 \\
\hline $\begin{array}{l}\text { Cleaning of the baby's teeth is not important, since they fall of after a few } \\
\text { years }\end{array}$ & $1,867(82.5)$ & 23.5 & 0.91 \\
\hline A child's overall health is not affected by cavities in the tooth/teeth & $2,000(88.4)$ & 25.6 & 1.07 \\
\hline A cavity should be filled only if it hurts the child & $1,709(75.1)$ & 24.1 & 2.39 \\
\hline $\begin{array}{l}\text { Tooth decay in baby teeth can cause infections that can spread to the face } \\
\text { and other parts of the body }\end{array}$ & $1,486(65.7)$ & 20.8 & 2.89 \\
\hline Regular visit to the dentist helps to prevent oral problems on the long run & $1,987(87.8)$ & 20.4 & 2.89 \\
\hline
\end{tabular}

\section{Discussion}

The present study assessed and co-related the oral health literature level and oral health knowledge. The literature is sparse regarding a national data on prevalence of oral health problems among pregnant women in India and the knowledge related to oral awareness is also inadequate., ${ }^{3,5-7}$ This highlights the need for more attention toward oral health among the pregnant women. Similar findings were reported by $\mathrm{US}^{10}{ }^{10}$ Nepal, ${ }^{2}$ and a few other Indian studies. ${ }^{3,6,7,11}$ A recent study from India reported that $40.9 \%$ of mothers from urban region were not aware that their oral health can affect the child also, ${ }^{4}$ which was in contrast to our study findings. The study in Brazil stated that those women with higher education qualification and greater access to information had better results in knowledge of oral health of their children, ${ }^{12}$ which was similar to our observations. A US study reported that a higher percentage of women were aware that it is important to clean the baby's teeth even if they fall eventually (98.0\%); $96.0 \%$ agreed that cavities in the teeth affected the overall health of the child; $92 \%$ said that one need not wait to fill the cavities only when it hurts; and $74 \%$ were aware that the infection from tooth decay can spread to the other parts of the child's body. ${ }^{10}$ These findings were similar to the responses we obtained in our study. We observed that educated women had correct knowledge regarding oral health, similar to the findings of the North Carolina study $^{10}$ and two other Indian studies. ${ }^{5-7}$ An estimated $29.9 \%$ of the women in our study were not sure whether tooth infection in a child can spread and affect other body parts. Also some of them carried on with the misconception that the baby's teeth need not be cleaned since they fall out eventually. The percentage of incorrect answers or don't-know responses ranged from 4.4 to $29.9 \%$. This points out that still lacuna is there to be focussed upon. For these pregnant women, a correct knowledge that is timely provided is a guide for a better health for both the mother and the child. ${ }^{3,7,13-15}$ A systematic review reported that access to dental care facilities is affected by many elements, including physiological conditions, low importance, negative stigma, fear toward dental treatment, financial barriers, lack of information, family and friend's advice, beliefs, and myths. ${ }^{16}$ Significant gaps in knowledge, misunderstandings, and a lack of dental care access exist for a majority of pregnant women across all socioeconomic levels, suggesting that better education of the importance of oral care before and during pregnancy is needed for all pregnant women., ${ }^{11,17}$ Pregnant women obtain information from various sources and are not restricted to only their general doctors. ${ }^{13,18}$ Unlike the West, India still remains in the back foot as far as providing guidance in oral health to pregnant women is concerned. ${ }^{11,17,19}$ There is strong evidence that health literacy is an effective way to overcome barriers to oral healthcare. ${ }^{16,20,21}$ Even though the policies in India focus on anemia, low birth weight, or breast-feeding practices, oral healthcare does not find any mention in any national policy or advisory. Also the gynecologists are not aware much about the oral health issues and hence advisories/statutory warnings or referrals to a dentist are far-fetched dreams. ${ }^{11}$ It is imperative that oral health becomes a part of the healthcare package provided to all the pregnant women. $2,3,7,10,11$ Advertisements by government regarding oral health on the similar grounds of abortions, safe pregnancy, as well as mother and child care should be carried out far and wide. There is a long-term positive impact of mother's knowledge on the oral health practices of the child. ${ }^{12}$ Even though we have special registries and facilities regarding obstetrics healthcare in India, dental health needs to be incorporated in the same. ${ }^{3}$ The cornerstone of a reduced disease burden with respect to prevention at an early stage starts with dental awareness and improved oral health practices among the pregnant women.

The study has certain limitations. The study was carried out in corporate hospitals where the patients are a creamy layer of people who already have better accessibility and a high literacy rate report for treatment. Hence these data may not hold true for those utilizing public healthcare system. We could not record the mode of information or knowledge that the participants used in order to obtain their knowledge, but surely it was not from their gynecologists. We did not validate the questions in the local language. Also, no oral examination was carried out. The oral findings would have definitely provided us with an impetus as to how much of the knowledge is being used for actual application in daily life by these women.

The study thus highlights the following points:

- The educated pregnant women had a high oral health literacy rate.

- Positive co relation of literacy with the REALD 30 score.

- Focus needs to be more on clearing the myths and misconceptions still prevalent in a small portion of the urban population.

\section{ACKnOWLedgments}

We thank all the participants of the study and the hospitals and staff who cooperated for the data collection.

\section{References}

1. Hartnett E, Haber J, et al. Oral Health in Pregnancy. J Obstet Gynecol Neonatal Nurs 2016;45(4):565-573. DOI: 10.1016/j.jogn.2016. 04.005 . 
2. Marla V, Srii R, et al. The Importance of Oral Health during Pregnancy: A review. Med Express 2018;5:1-6. DOI: 10.5935/medicalexpress.2018. mr.002.

3. Gupta R, Acharya AK. Oral Health Status and Treatment Needs among Pregnant Women of Raichur District. Scientifica (Cairo) 2016;2016:9860387. DOI: 10.1155/2016/9860387.

4. Chaitra T, Wagh S, et al. Knowledge, Attitude and Practice of Oral Health and Adverse Pregnancy Outcomes among Rural and Urban Pregnant Women of Moradabad, Uttar Pradesh, India. J Interdiscip Dent 2018;8(1):5. DOI: 10.4103/jid.jid_56_17.

5. Payal S, Kumar G, et al. Oral health of pregnant females in central India: Knowledge, awareness, and present status. J Educ Health Promot 2017;6(1):102. DOI: 10.4103/jehp.jehp_146_16.

6. Jain D, Agrawal N, et al. Dental Health Care in Pregnancy: A Survey And Literature Review. Int J Sci Res 2016;15(6):91-95. DOI: 10.9790/08531506039195.

7. Chawla RM, Shetiya SH, et al. Knowledge, attitude, and practice of pregnant women regarding oral health status and treatment needs following oral health education in Pune District of Maharashtra: A longitudinal hospital-based study. J Contemp Dent Pract 2017;18(5):371-377. DOI: 10.5005/jp-journals-10024-2049.

8. Boggess KA, Edelstein BL. Oral health in women during preconception and pregnancy: Implications for birth outcomes and infant oral health. Matern Child Health J 2006;10(Suppl 7):169-174. DOI: 10.1007/ s10995-006-0095-x.

9. Bamanikar S, Kee LK. Knowledge, attitude and practice of oral and dental healthcare in pregnant women. Oman Medical Journal 2013;28(4):288-291.

10. Hom JM, Lee JY, et al. Oral health literacy and knowledge among patients who are pregnant for the first time. J Am Dent Assoc 2012;143(9):972-980.

11. Nagaraj A, Pareek S. Infant Oral Health Knowledge and Awareness: Disparity among Pregnant Women and Mothers visiting a Government Health Care Organization. Int J Clin Pediatr Dent 2012;5(3):167-172. DOI: 10.5005/jp-journals-10005-1160.
12. Rigo L, Dalazen J, et al. Impact of dental orientation given to mothers during pregnancy on oral health of their children. Einstein (Sao Paulo) 2016;14(2):219-225. DOI: 10.1590/s1679-45082016ao3616.

13. Akbarinejad F, Soleymani $M$, et al. The relationship between media literacy and health literacy among pregnant women in health centers of Isfahan. J Educ Health Promot 2017;6(1):17. DOI: 10.4103/22779531.204749.

14. Oral Health Care During Pregnancy Expert Workgroup. Oral Health Care During Pregnancy: A National Consensus Statement. Natl Matern Child Oral Heal Resour Cent 2012;2012:1-2, http://www. mchoralhealth.org.

15. Buerlein J. Awareness of Oral Health Among Pregnant Women and New Mothers: Preliminary Findings Children's Dental Health Project.

16. Rocha J, Arima L, et al. Barriers and facilitators to dental care during pregnancy: a systematic review and meta-synthesis of qualitative studies. Cad Saude Publica 2018;34(8):e00130817. DOI: 10.1590/0102311x00130817.

17. Amin R, Shetty $P$, et al. Oral Health Status During Pregnancy in Mangaluru. Nitte Univ J Heal Sci 2014;4(2):2249-7110, http://nitte. edu.in/journal/June2014/114-117.pdf.

18. Ravishankar T, Chaitra T, et al. Mother's knowledge about pre-school child's oral health. J Indian Soc Pedod Prev Dent 2011;28(4):282. DOI: 10.4103/0970-4388.76159.

19. Sohi $R$, Talwar $D$, et al. Oral health status and adverse pregnancy outcomes among pregnant women in Haryana, India: A prospective study. J Indian Assoc Public Heal Dent 2015;13(2):138. DOI: 10.4103/2319-5932.159049.

20. Vann WF, Lee JY, et al. Oral health literacy among female caregivers: Impact on oral health outcomes in early childhood. J Dent Res 2010;89(12):1395-1400. DOI: 10.1177/0022034510379601.

21. Sharma G, Sowmya K, et al. Association between oral health literacy and oral health-related quality of life among undergraduate students in Bengaluru city. J Indian Assoc Public Heal Dent 2014;12(3):209. DOI: 10.4103/2319-5932.144801. 